\title{
Education on Correct Inhaler Technique in Pharmacy Schools: Barriers and Needs
}

\author{
Iman A Basheti ${ }^{1 *}$, Anas I Natsheh ${ }^{1}$, Wesam G Ammari ${ }^{2}$, Samar Khater ${ }^{1}$, Eyad A \\ Qunaibi ${ }^{1}$ and Sinthia Z Bosnic-Anticevich ${ }^{3}$ \\ ${ }^{1}$ Faculty of Pharmacy, University of Applied Sciences, ${ }^{2}$ Faculty of Pharmacy, Al-Ahliyya Amman University, Amman, Jordan, \\ ${ }^{3}$ Sydney Medical School and Woolcock Institute of Medical Research, University of Sydney, NSW, Australia \\ *For correspondence: Email: dr_iman@asu.edu.jo; Tel: +9626 5609999 ext 1737, +962 799048003 ; Fax: +9626 5515017
}

\begin{abstract}
Purpose: To investigate the effectiveness of a standard educational module on pharmacy students' inhaler technique demonstration skills.

Methods: This investigational study was conducted during the Clinical Pharmacy and Therapeutics tutorial classes in 2011. All fifth-year students were given placebo inhaler devices and information leaflets explaining the use of these devices. Students were then shown, by demonstration, the correct technique for each of the inhalers. All the students were assessed on the use of each of the inhalers two weeks following the tutorial. A validated questionnaire regarding the students' barriers to demonstrate the correct inhaler technique was completed by all the students. The inhaler techniques demonstrated were Accuhaler (ACC), Turbuhaler (TH) and metered-dose inhaler (MDI).

Results: Students scored significantly better with ACC with a score of $4.38 \pm 1.81$ (out of 9.00) than with TH (3.96 \pm 1.75 out of 9.00$) ; p=0.004$, and MDI (2.69 \pm 1.76 out of 8.00$) ; p<0.001$, based on Friedman test 2 weeks following training. The majority of students (78\%) believed that lack of practice with the devices was the primary barrier to correct inhaler use.

Conclusion: Standard educational training may not be the most appropriate method of teaching students the correct use of inhalers. Clearly, there is a practice element missing which needs to be addressed in a feasible way.
\end{abstract}

Keywords: Inhaler technique, Pharmacy education, Hands-on training, Training barrier

Tropical Journal of Pharmaceutical Research is indexed by Science Citation Index (SciSearch), Scopus, International Pharmaceutical Abstract, Chemical Abstracts, Embase, Index Copernicus, EBSCO, African Index Medicus, JournalSeek, Journal Citation Reports/Science Edition, Directory of Open Access Journals (DOAJ), African Journal Online, Bioline International, Open-J-Gate and Pharmacy Abstracts

\section{INTRODUCTION}

Asthma is a chronic disease resulting from widespread narrowing of the airways within the lungs and obstruction to airflow [1]. In Jordan, studies have shown that in the last decade, asthma prevalence has increased about twofold $[2,3]$. Fortunately, patients can get an optimal control of their lung disease with effective treatment using different inhaler therapies [4]. However, patients need to use the correct inhaler technique to get the desired outcome of their inhaled medicines [5]. Patients prescribed inhaled treatments require careful instruction when their inhaler medications are dispensed $[6,7]$. Lack of, or improper patient education on inhaler technique leads to the inability of the patients to use their inhalers correctly, contributing to asthma mortality and morbidity [8]. Pharmacists are in a pivotal position to deliver this needed education on correct inhaler technique, as they are the last health care professionals to see the patient before they start using their inhalers. However, pharmacists in 
Jordan and around the world have suboptimal skills in demonstrating and hence educating patients on the correct use of their inhaler devices [9].

In pharmacy schools, where undergraduate pharmacy students' preliminary knowledge is obtained, inhaler technique education is initiated. Different methodologies have been investigated to optimize inhaler technique demonstration skills amongst pharmacy students; however, none have been able to achieve the outcomes expected $[10,11]$.

The aim of this study was to investigate the impact of a standard educational tutorial (verbal information about inhaler technique plus a physical demonstration of the technique) on undergraduate pharmacy students' ability to demonstrate correct use of inhaler devices; in addition, students' perceived barriers to demonstrating correct use of the inhalers before graduating from pharmacy schools were investigated.

\section{EXPERIMENTAL}

\section{Study setting}

This was a prospective investigational study that was approved by the University of Applied Sciences' Ethics Committee. It was conducted during the Clinical Pharmacy and Therapeutics tutorial classes from November to January 2011. Administrative approval was obtained for the study from the Faculty of Pharmacy. The study included all the students enrolled in this tutorial who were in the 5th year of their Bachelor of Pharmacy degree curriculum. Within this unit of study, the students were divided into 4 tutorials. Each student attended one Clinical Pharmacy and Therapeutics tutorial per week for 10 weeks. Over this 10 weeks period, tutorials were conducted in respiratory health, cardiovascular disease (hypertension, ischemic heart disease, and cardiac failure), endocrinology (diabetes and thyroid disorders), infectious diseases, and in the areas of communication skills, barriers to communication, patient counseling and patient perspectives to illness.

Each tutorial was facilitated by one tutor (a community pharmacist) and one lecturer (IB, $\mathrm{PhD}$ in Clinical Pharmacy) and lasted for 3 hours. Tutorials were spread out through the week and included problem-based learning approaches as well as appropriate hands-on and small group activities [12]. The students enrolled in this course unit were evaluated through an end-of- semester oral assessment, multiple-choice and written examinations and throughout semester tutorial participation.

\section{Study design}

In the 6th weeks of the semester, following completion of the respiratory lecture material delivery, all students were invited to participate in the study and asked to sign an informed consent form. In the respiratory lectures, students were presented with the image of each inhaler type found in the market next to a checklist showing its technique steps). At the start of the tutorial, each participant was invited to spend few minutes with a researcher. Each student was handed a placebo inhaler device, MDI, TH and ACC, and asked to demonstrate the correct technique for each of the devices randomly. Placebo inhalers were made available by AstraZeneca (Amman, Jordan) and GlaxoSmithKline (Amman, Jordan). Students were allowed to decline from demonstrating any of the device techniques if they did not know how to operate the device.

During this time, students not being assessed were asked to complete a questionnaire designed to collect data regarding demographic characteristics including age, gender, hours spent in undergraduate pharmacy training and place of training (community and hospital pharmacies), beliefs regarding pharmacists' role in identifying patients with health problems arising from incorrect use of treatment, and the pharmacist role with regards to inhaler technique training.. Students' previous personal use of any of the study inhaler devices was also questioned, with their confidence level (a choice between 'not confident', 'confident' and very confident') in counselling patients on each of these inhalers.

Students' asthma knowledge was evaluated via an asthma knowledge questionnaire (AKQ) [13]. $A K Q$, comprised 18 true/false questions about asthma and its treatment, was exactly employed as published by Kritikos et al [13] with the exclusion of question 12 (about an Australiaspecific incentivized GP program). The AKQ score was, presented in the current study as mean score (SD) out of 17 . All questionnaires were administered in English language since it is the official language of pharmacy education in all Jordanian Universities.

Additionally, $2 \mathrm{~h}$ following the completion of the AKQ original English version, and before discussing its answers, the students were asked to complete an Arabic version of the AKQ. The $A K Q$ questionnaire was previously translated into 
Arabic and validated for clarity by the study researchers. This was done to assess if language was a barrier in this study.

After baseline assessment was completed, each student was provided with the three placebo inhalers and three information leaflets explaining the use of each of the study device (package insert product information). Each participant was given $15 \mathrm{~min}$ to read the leaflets for the three devices and to apply the technique to the inhalers provided to them (referring only to the written resources provided). Participants were not instructed on how or what to do with the placebo devices, nor how to use the written information provided. Participants utilized their own learning techniques.
The inhaler technique for each of the devices was then demonstrated by the tutor to all the students, with verbal explanation of the steps. The students were then given $15 \mathrm{~min}$ to practice the use of these devices individually. Students were blinded to the fact that a follow-up assessment was going to take place (Figure 1).

Two weeks after this education, all students were assessed again on their inhaler technique demonstration skills for the three devices. Inhaler technique was assessed by the same assessor, experienced in inhaler technique education, to avoid integrator variability. Inhaler technique assessment for each inhaler (MDI, TH and ACC) was based on a specific checklist for each inhaler device derived from published literature (Table 1) [14,15].

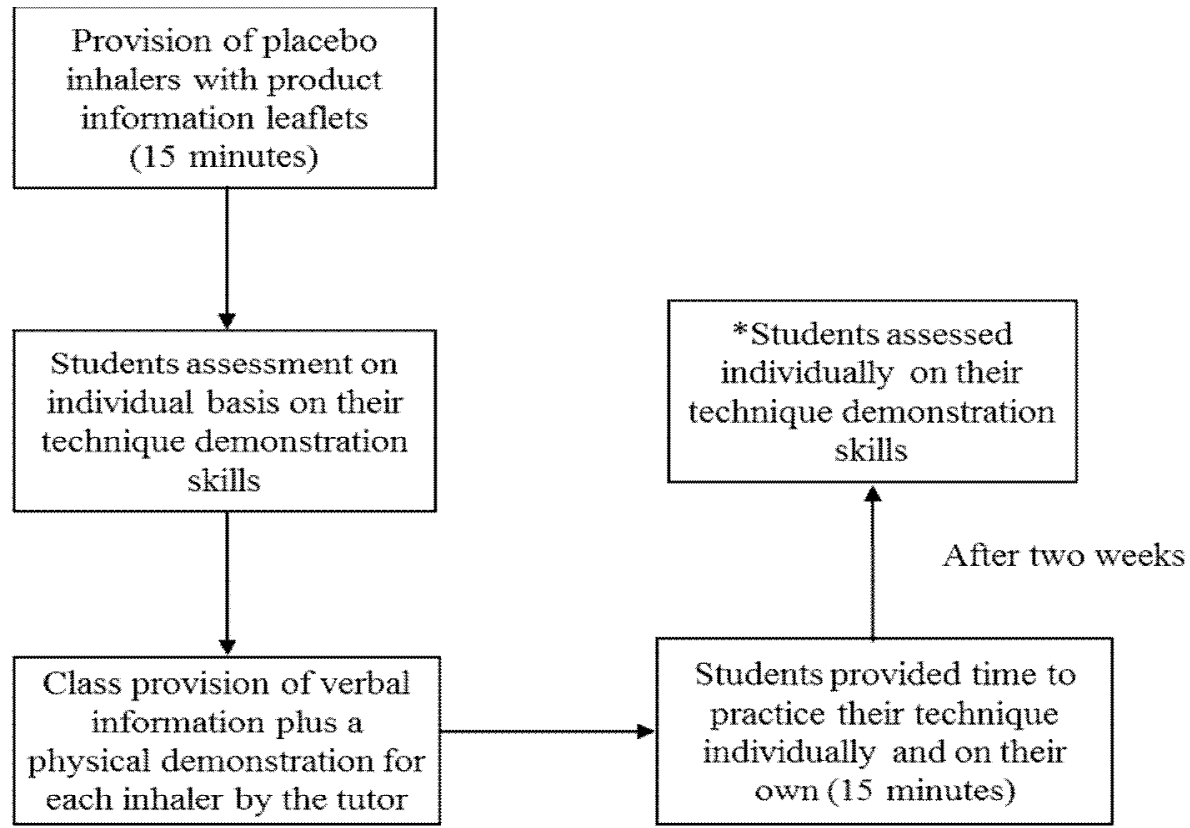

* Student were blinded to the fact that a follow-up assessment of their inhaler technique demonstration skills was going to take place.

Figure 1: Standard educational method of inhalers' use applied in the Schools of Pharmacy on the inhalers techniques demonstration skills

The participants were given 1-point score for each step they performed correctly. The correct inhaler technique corresponded to a score of $8 / 8$ for MDI, 9/9 for TH and 9/9 for ACC.

A structured questionnaire was designed to collate data regarding the students' perceived barriers to demonstrating correct inhaler technique following education in their pharmacy school and any suggestions relating to new educational strategies in this area. To ensure face validity, this questionnaire was evaluated prior to the current study by three academics that have extensive experience in conducting clinical studies and a wide range of professional clinical experience. The questionnaire was administered to a random sample of pharmacy students $(n=$ 15) to test for the clarity of its items. Views and comments of those students were analyzed by the researchers and then incorporated, where appropriate, into the final version of the questionnaire used in this study.

The questionnaire was administered at the end of the second tutorial, following student's final assessment of their inhaler technique. 
Table 1: Inhaler technique checklists

Nine-point Accuhaler Technique Checklist Step. Description/action

1. Open Inhaler

2. Push lever back completely

3. Exhale to residual volume

4. Exhale away from mouthpiece

5. Place Mouthpiece between teeth and lips

6 . Inhale forcefully and deeply

7. Hold breath for 5 seconds

8. Exhale away from mouthpiece

9.Close inhaler

Nine-point Turbuhaler Technique Checklist

\begin{tabular}{l}
\hline Step. Description/action \\
\hline 1. Remove the cap from the Inhaler \\
2. Keep inhaler upright \\
3. Rotate grip until a click is heard \\
4. Exhale to residual volume \\
5. Exhale away from mouthpiece \\
6. Place mouthpiece between teeth and lips \\
7. Inhale forcefully and deeply \\
8. Hold breath for 5 seconds* \\
9. Exhale away from mouthpiece
\end{tabular}

Eight-point MDI Technique Checklist

\section{Step. Description/action}

1. Remove mouthpiece cover and shake

2. Hold inhaler upright

3. Exhale to residual volume

4. Keep head upright or slightly tilted

5. Place mouthpiece between teeth and lips

6 . Inhale slowly and press canister

7. Continue slow and deep inhalation

8. Hold breath for 5 seconds

Note: These checklists are based on previously published checklists [14,15]. * This step is not included in the product insert but appears in the Turbuhaler instructions on the Global Initiative for Asthma Website [1], and in the checklist from van der Palen and colleagues [5].

\section{Data analysis}

The data was analyzed using the Statistical Package for Social Science (SPSS) version 17. Demographic data, including gender, age, hours spent in pharmacy training, years spent in undergraduate pharmacy studies, inhaler use history and confidence in using the inhaler devices were analyzed descriptively. The mean \pm standard error values and the $95 \%$ confidence interval $(\mathrm{Cl})$ were used to describe the normally distributed continuous data (normality of distribution was determined using the Kolmogorov-Smirnov test). For non-normally distributed data, non-parametric tests were used (Friedman test for comparisons of inhaler technique scores within group, and Mann Whitney $U$ test for comparisons between groups). Proportional data was analyzed using Pearson's Chi-Square test (or Fisher's exact test). For all statistical analysis, $p \leq 0.05$ was considered statistically significant.

In order to determine the predictors of correct inhaler technique, a backwards multiple regression analysis was performed for each of the inhalers. The dependent variable was inhaler technique score. The independent variables included gender, age, previous pharmacy experience (hours), years spent so far in the undergraduate pharmacy studies, previous inhaler use (yes/no), confidence in demonstrating the use of the inhaler before educational intervention (very confident, confident, and not confident) and AKQ (English version) scores.

\section{RESULTS}

Seventy-eight pharmacy students (55.6\% females), enrolled in the Clinical Pharmacy and Therapeutics II module, participated in the study with a mean age $( \pm S D)$ of $23.46 \pm 0.22$ years.

Regarding the time spent in undergraduate studies, $77.8 \%$ of the participants were in their 5 th (final) year of their undergraduate pharmacy study. Whilst, $14.8 \%$ of the participants were 4 th year students who had excelled in their studies and had completed other prerequisite modules. A small proportion $(7.4 \%)$ of the participating students was repeating this module due to a previous failure.

The mean \pm SD time spent in pharmacy training was $1084.7 \pm 474.6 \mathrm{~h}$. Majority $(69.1 \%)$ of the participants spent these practice hours at community pharmacies, $12.3 \%$ had their training at hospital pharmacies, whereas $4.9 \%$ practiced at both community and hospital pharmacies.

With regards to previous inhaler use, $9.0 \%$ of the students had previously used an MDI, $5.1 \%$ had used a TH and $2.6 \%$ had used an ACC. The most common reason for previous use was for personal asthma treatment.

More students reported feeling very confident/confident in demonstrating the MDI technique $(64.1 \%)$ as compared to the DPIs, ACC (62.8\%), TH (61.6\%). No significant differences were found between the 3 inhalers with regards to the students' confidence levels (Table 2).

For asthma knowledge (AKQ score out of 17) [13], the students' mean \pm SD score was $9.05 \pm$ 2.45 with no significant differences between males and females or the students' time spent in 
undergraduate studies $(p>0.05$, Independent Sample $T$ test). The scores of the AKQ Arabic version were very similar to the English version (mean \pm SD: $8.61 \pm 1.65$ ), with no significant differences found ( $p=0.591$, Wilcoxon Signed Rank test).

Table 2: Proportion of Students $(n=78)$ who reported perceived confidence in demonstrating the correct use of the inhaler devices

\begin{tabular}{lccc}
\hline $\begin{array}{l}\text { Level of } \\
\text { confidence (\%) }\end{array}$ & MDI $^{*}$ & TH $^{*}$ & ACC* \\
\hline Very confident & $10.3 \%$ & $10.3 \%$ & $11.5 \%$ \\
Confident & $53.8 \%$ & $51.3 \%$ & $51.3 \%$ \\
Not confident & $35.9 \%$ & $38.5 \%$ & $37.2 \%$ \\
\hline
\end{tabular}

*No significant differences were found between the inhaler groups with regards to students reported confidence $(p>0.05$, Chi square test)

For the majority of students (78\%), the main perceived barriers to learning and demonstrating the correct inhaler technique was the lack of practice with the inhaler devices, especially while engaging with real asthma patients. The remaining percentage of the students believed that their lack of knowledge about the importance of patients' inhaler technique education was the main barrier (Table 3 ).

Students' inhaler technique demonstration skills At baseline before any education was delivered, majority of students declined from demonstrating the administration technique for any of the devices due to their unfamiliarity with it $(6.4 \%)$. Only students who reported previous inhaler use due to personal asthma treatment agreed to demonstrate the technique at this stage $(9.0 \%)$. From the students who agreed to demonstrate the use of the three devices, only three demonstrated the correct technique for the MDI $(3.8 \%)$, two for the ACC $(2.6 \%)$ and none for the $\mathrm{TH}$.

Following the standard education delivered, none of the students performed all the inhaler technique steps correctly as per the checklists of the studied inhaler devices.

There was a difference in their ability to use the different inhalers. Students scored significantly better with the ACC (score $4.38 \pm 1.81$ (out of 9)) than with the TH (score $3.96 \pm 1.75$ (out of 9)); $p$ $=0.004$, and the MDI $(2.69 \pm 1.76$ (score out of $8)$ ); $p<0.001$, Friedman test.

Female students performed significantly better than the male students for the ACC $(4.76 \pm 1.86$ vs. $3.78 \pm 1.59 ; p=0.042)$, and the MDI (3.24 \pm 1.70 vs. $2.09 \pm 1.64, p=0.005$ ).

The number of students performing each of the steps correctly for each of the inhaler devices is shown in Figures $2 \mathrm{~A}, 2 \mathrm{~B}$ and $2 \mathrm{C}$. For the $\mathrm{ACC}$, the most common error performed by the students in the inhaler technique was in step 3 (Exhale to residual volume) and Step 8 (Exhale away from mouthpiece). Whereas for the TH technique, the most commonly made mistakes were step 4 (exhale to residual volume) and step 9 (Exhale away from mouthpiece). For the MDI technique, the most common errors were in step 4 (Keep head upright or slightly tilted) and step 7 (Continue the "slow and deep" inhalation through the inhaler).

There was no significant association between inhaler technique with other variables such as ACC $\left(R^{2}=0.209, p=0.78\right)$, TH $\left(R^{2}=0.0338, p=\right.$ $0.713)$ and $M D I\left(R^{2}=0.428, p=0.21\right)$; the AKQ score was the only variable that was significantly associated with higher MDI technique scores (B $=-0.455, \mathrm{t}=2.146, p=0.042$ ).

A majority of the students (95.4\%) believed that it is their role "as pharmacists" to identify patients with health problems arising from incorrect use of treatment. All students (100\%) believed that it is their role to demonstrate to their patients the correct use of their inhaler devices.

Table 3: Perceived barriers by pharmacy students $(n=78)$ to using the inhaler devices correctly and hence demonstrating their correct use following in class education on correct inhaler technique

\begin{tabular}{ll}
\hline Frequency (\%) & Identified barrier \\
\hline 78.2 & Insufficient in class practice with the inhaler placebo devices \\
60.3 & Insufficient practice with real asthma patients using these devices \\
52.6 & Lack of knowledge about the importance of this issue to asthma patients \\
25.6 & Believe that it's not needed as this type of counseling is not applicable in Jordanian pharmacies \\
15.4 & Believe that it's not needed as patients won't accept this type of counseling from pharmacists \\
10.3 & Believe that it's not needed as inhaler technique education is the responsibility of the pharmacist \\
7.7 & assistant and not the pharmacist \\
3.8 & Believe that it's not needed as inhaler technique education is the responsibility of the specialist only and \\
& interfering can create conflict \\
\hline
\end{tabular}




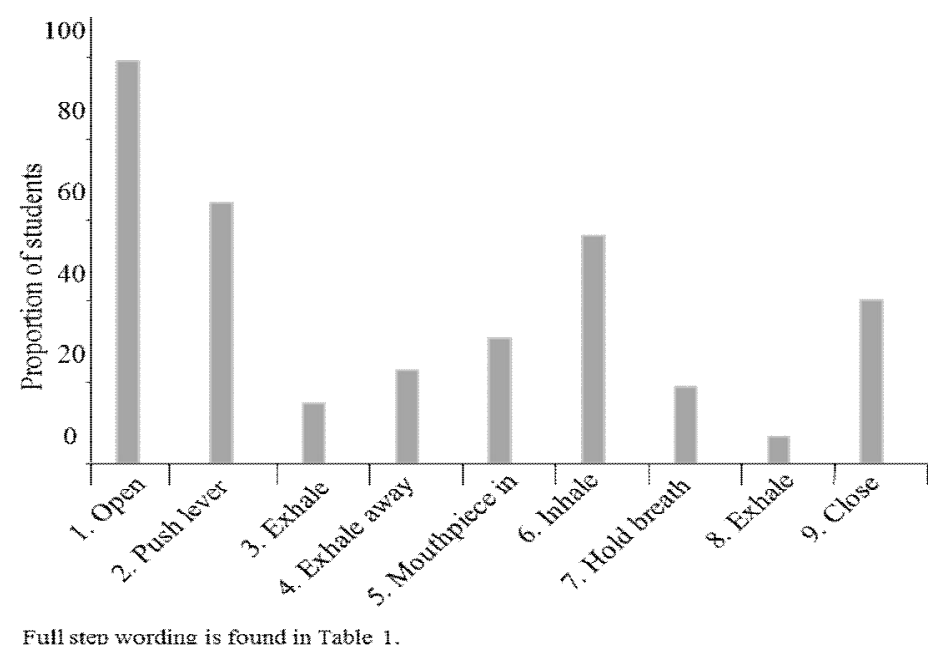

Figure 2A: Proportion of students who demonstrated correctly each of the steps in the Accuhaler technique checklist.

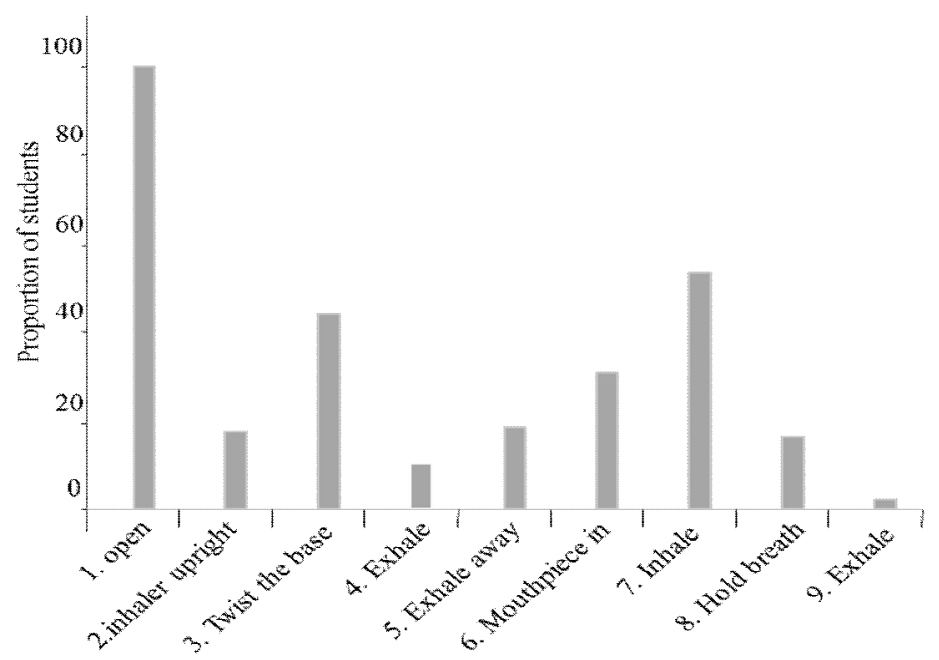

Full step wording is found in Table 1.

Figure 2B: Proportion of students who demonstrated correctly each of the steps in the Turbuhaler technique checklist.

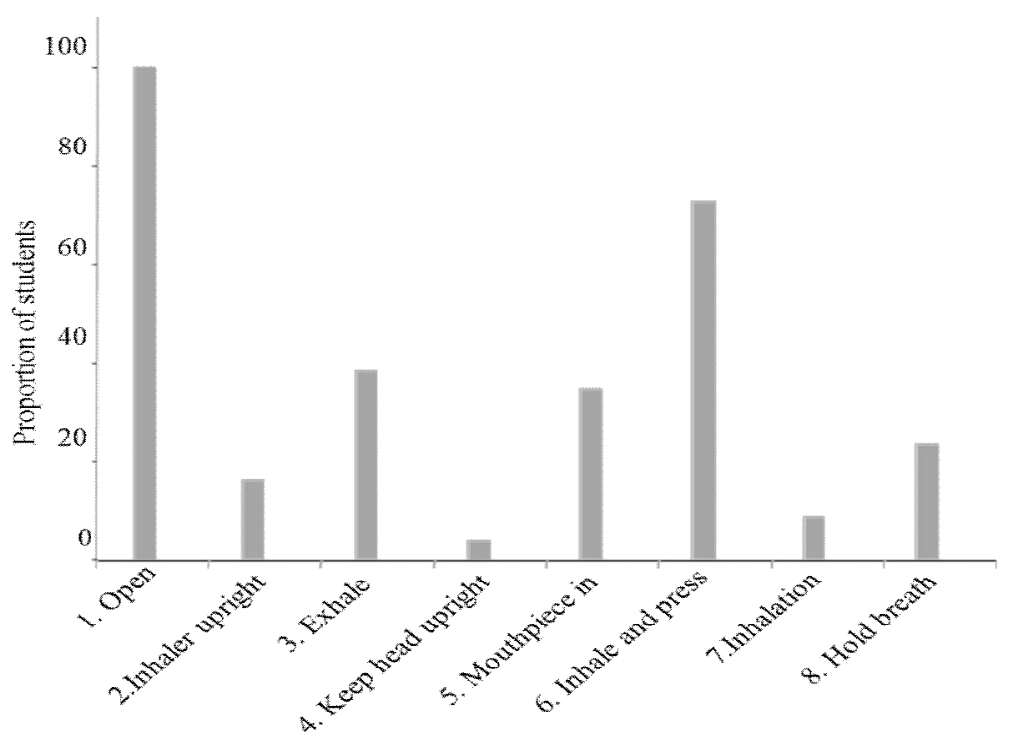

Figure 2C: Proportion of students who demonstrated correctly each of the steps in the MDI technique checklist 


\section{DISCUSSION}

This study has shown that the current standard education of inhaler administration techniques delivered in the Clinical Pharmacy and Therapeutics tutorials was not sufficient to provide the pharmacy students with the skills needed to demonstrate the correct use of these devices. The students did report that it was not adequate to receive a verbal education along with an inhaler technique demonstration. They identified different barriers to learning the correct technique for the inhaler devices; these barriers can be the cornerstone for the development of better future education and training strategies in this domain. The insufficient in-class practice, the lack of engagement with real patients that use these inhalers, and the lack of knowledge about the importance of this therapeutic area were the main barriers acknowledged by the students. Engaging pharmacy students with real patients counseling [16] and providing them with a feasible and practical educational strategy to deliver to these patients [17] can eliminate many of the barriers identified in this study.

This study showed no correlation between the pharmacy students' self-confidence and their demonstration of a correct inhaler technique, which is consistent with previous findings [10]. This could be due to the fact that at this stage, the students did not completely grasp the concept of what a correct technique involves; hence, they were not able to reasonably judge their own confidence in demonstrating the correct use of the inhalers. Asking the students about their ability and confidence in using the inhaler devices does not elicit a reliable response before they are completely aware of what a correct inhaler technique is.

Differences were seen in the technique demonstration skills of the three inhaler devices. The students performed better with the newer DPIs (ACC and TH introduced to the Jordanian market in 2002) than with the older, widelyprescribed pMDIs (introduced to the market in the 1970s). Better performance with the newer devices could be due to their easier technique to learn from the product information leaflets. For the ACC and TH, no association was found between the students' inhaler technique scores and their demographic characteristics, previous use of the devices, confidence in demonstrating the correct use for these devices and the AKQ scores whilst a significant correlation was found between the students' MDI technique scores and their AKQ scores. This indicates that the students with better asthma knowledge were able to better demonstrate the correct MDI technique. This could be due to the fact that in the class room, where asthma education was delivered, more focus was directed towards the good use of the commonly prescribed MDI and resolving its related technique issues.

When it comes to the problematic inhaler steps; exhaling to the residual volume before inhaling via the inhaler and exhaling away from the device as problematic steps both in the ACC and $\mathrm{TH}$ users were consistent with the findings of many other related studies [10]. Keeping the head tilt upright and not breathing in slowly and deeply via the MDI were the common problematic MDI steps made by the student. In this, students were not different to actual inhaler users. Both steps are essential for a sufficient lung deposition [15]. Therefore, future clinical pharmacy educational tutorials need to highlight all these inhaler technique mistakes.

\section{Limitations of the study}

This study had a number of limitations; the evaluation of the study educational intervention was conducted in one pharmacy school in Jordan using one cohort of fifth-year undergraduate pharmacy students. However, no major differences can be found in the related educational methodologies used in other schools of pharmacy that can limit the generalization of the findings of this study. Future studies need to investigate ways to overcome the identified barriers unveiled in this study with enhanced educational and training strategies able to improve the pharmacy students' competency and confidence in counseling their asthma patients on the correct inhalers techniques once they graduate and start practicing pharmacy. A possible solution would be to include inhaler technique demonstration into vocational training to be signed off.

\section{CONCLUSION}

The standard educational method of teaching pharmacy student inhaler technique investigated in this study is not sufficient to provide the student with sufficient skills to correctly demonstrate the use of various MDI and DPI devices. The main barriers to demonstrating correct inhaler technique identified by the students include insufficient in-course practice with the inhalers and inadequate practice with real patients. These barriers need to be resolved in order to achieve better future results in this regard. 


\section{ACKNOWLEDGEMENT}

This study was funded by the Deanship of Academic Research, Applied Sciences University, Amman, Jordan. The authors wish to thank the students who participated in this study.

\section{REFERENCES}

1. Global Initiative for Asthma (GINA) - Global Strategy for Asthma Management and Prevention - Revised Workshop Report 2012. [Cited May 2014]. Available online at: http://www. ginasthma.org.

2. Abuekteish F, Alwash R, Hassan M, Daoud AS. Prevalence of asthma and wheeze in primary school children in northern Jordan. Ann Trop Paediatr 1996; 16(3): 227-231.

3. Abu-Ekteish F, Otoom S, Shehabi I. Prevalence of asthma in Jordan: comparison between Bedouins and urban schoolchildren using the International Study of Asthma and Allergies in Childhood phase III protocol. Allergy Asthma Proc 2009; 30(2): 181-185.

4. Barnes PJ. Achieving asthma control. Curr Med Res Opin 2005; 21 Suppl 4: S5-9.

5. van der Palen J, Klein JJ, Schildkamp AM. Comparison of a new multidose powder inhaler (Diskus/Accuhaler) and the Turbuhaler regarding preference and ease of use. J Asthma 1998; 35(2): 147-152.

6. Basheti IA, Armour CL, Bosnic-Anticevich SZ, Reddel HK. Evaluation of a novel educational strategy, including inhaler-based reminder labels, to improve asthma inhaler technique. Patient Educ Couns 2008; 72(1): 26-33.

7. Basheti IA, Reddel HK, Armour CL, Bosnic-Anticevich SZ. Counseling about turbuhaler technique: needs assessment and effective strategies for community pharmacists. Respir Care 2005; 50(5): 617-623.

8. Giraud V, Allaert FA, Roche N. Inhaler technique and asthma: feasibility and acceptability of training by pharmacists. Respir Med 2011; 105(12): 1815-1822.
9. Basheti IA, Qunaibi E, Bosnic-Anticevich SZ, Armour CL, Khater S, Omar M, Reddel HK. User error with Diskus and Turbuhaler by asthma patients and pharmacists in Jordan and Australia. Respir Care 2011; 56(12): 1916-1923.

10. Toumas M, Basheti IA, Bosnic-Anticevich SZ. Comparison of small-group training with self-directed internet-based training in inhaler techniques. Am J Pharm Educ 2009; 73(5): Article 85.

11. Dominelli GS, Dominelli PB, Rathgeber SL, Webster SB. Effect of different single-session educational modalities on improving medical students' ability to demonstrate proper pressurized metered dose inhaler technique. J Asthma 2012; 49(4): 434-439.

12. Basheti IA, Qunaibi EA, AbuRuz S, Samara S, Bulatova NR. Home medication reviews in a patient care experience for undergraduate pharmacy students. Am J Pharm Educ 2013; 77(8): 173.

13. Kritikos V, Saini B, Bosnic-Anticevich SZ, Krass I, Shah S, Taylor S, Armour C. Innovative asthma health promotion by rural community pharmacists: a feasibility study. Health Promot J Austr 2005; 16(1): 69-73.

14. Basheti IA, Bosnic-Anticevich SZ, Armour CL, Reddel HK. Checklists for Powder Inhaler Technique: A Review and Recommendations. Respir Care 2014; 59(7): 1140-1154.

15. Bosnic-Anticevich SZ, Sinha $H$, So $S$, Reddel HK. Metered-dose inhaler technique: the effect of two educational interventions delivered in community pharmacy over time. J Asthma 2010; 47(3): 251-256

16. Basheti IA. Bridging the gap between theory and practice: effect of simulation in training pharmacy students on correct device technique. Am J Pharm Edu 2014; 'in press'.

17. Odedina FT, Segal $R$, Hepler $C D$. Providing pharmaceutical care in community practice: Differences between providers and non-providers of pharmaceutical care. J Soc Admin Pharm 1995; 12(4): $170-180$. 